\title{
Classification of EU countries according to the degree of the sustainable development goals achievement related to agriculture
}

\author{
Radka Nenova ${ }^{1 *}$ \\ ${ }^{1}$ D.A. Tsenov Academy of Economics, Department of Agricultural Economics, 5250 Svishtov, 2 Em. \\ Chakarov Str., Bulgaria
}

\begin{abstract}
The main goal of the study is to classify the 27 countries of the European Union (excluding the UK) according to their contribution to achieving the UN's global goals for sustainable development related to agriculture. Five goals were selected: Goal 2: Zero hunger, Goal 3: Good health and well-being, Goal 12: Responsible consumption and production, Goal 14: Life below water and Goal 15: Life on land. The following criteria for distinguishing countries were used in the clustering: Goal achievement, Challenges remain, Significant challenges, Major challenges. To achieve this goal, from a methodological point of view, are applied: correlation analysis, cluster analysis, ANOVA analysis of variance and post hog test for multiple comparison - Tukey HSD. As a result of the analysis, with data from the Sustainable Development Report 2020, four clusters were identified. Bulgaria falls into the second cluster, along with Croatia, Cyprus, Finland, France, Greece, Ireland and Sweden. The main conclusion for countries in the second cluster is that there are significant challenges for Goal 2 and Goal 14, challenges remain for Goal 3 and Goal 15 and major challenges for Goal 12.
\end{abstract}

\section{Introduction}

The United Nations (UN) has formulated Millennium Development Goals, aimed at eradicating poverty and for the period $2000-2015$ progress has been reported - reducing poverty rates by half. Over the next fifteen years, by 2030, the UN's goals will grow into a need of transformation towards a better and more sustainable future for all. Sustainable future involves solving the food problem which in turn means that it is directly related to agriculture. From this point of view, the aim of the present study is to classify the countries of the European Union (EU) according to the degree of achievement of the UN's Sustainable Development Goals (SDGs) related to agriculture. The following research tasks have been formulated for its implementation: 1) determining SDGs related to agriculture; 2) theoretical and methodological review of existing scientific publications and determination of the stages of the research; 3 ) characteristics and comparison of the identified clusters. The object of the study is the sustainable development of agriculture in the EU countries, and the subject -

* Corresponding author: $\underline{\text { r.nenova@uni-svishtov.bg }}$ 
classification of European countries on the basis of similarities/differences in the degree of achievement of SDGs related to agriculture.

\section{The Global Goals for Sustainable Development and Agriculture}

Internationally, one of the global challenges facing humanity is to achieve sustainable development and eradicate poverty. In October 2015, the United Nations (UN) adopted the 2030 Agenda [1], which defines a set of 17 SDGs and practical tasks related to them. The Agenda states that the tasks are recommended but concern all countries and individual governments must define their own national tasks, which should be reflected in national policies, strategies and planning processes.

In Bulgaria, for five years after the adoption of the UN Agenda until 2030, a unified national strategy for sustainable development has not been developed. In parallel, a sectoral approach is being applied. At the end of 2020, the Council of Ministers adopted the National Development Programme BULGARIA 2030 [2]. The National Programme is a strategic framework document in which the vision and general goals of the development policies of all sectors of government are determined. The document systematizes three strategic goals and groups five areas of development and thirteen national priorities, respectively. A significant element of the National Programme is that the description of the priorities also indicates their relevance to the UN SDGs.

The sixth priority in the National Programme BULGARIA 2030 is "Sustainable Agriculture". In Table 1, the traced sub-priorities, the areas of impact and the relevant UN SDGs are systematized. From the data in Table 1, it can be summarized that for the functioning of Bulgarian agriculture in a sustainable way, with a horizon of 2030, it is necessary to achieve sectoral balance, increase the income of farmers and the competitiveness of the industry, strengthen the role of agriculture in environmental protection and implement targeted actions in fisheries and aquaculture management.

Table 1. Priorities for the development of sustainable agriculture until 2030

\begin{tabular}{|c|c|c|}
\hline Sub-priority & Area of impact & Relevant SDGs \\
\hline \multirow{5}{*}{$\begin{array}{l}\text { 6.1. Structural } \\
\text { and sectoral balance } \\
\text { of agriculture }\end{array}$} & 6.1.a Plant-growing & \multirow{6}{*}{ Goal 2 (sub-goal 2.3) } \\
\hline & 6.1.b Livestock farming & \\
\hline & 6.1.c Economic potential of small farms & \\
\hline & 6.1.d Age structure of farmers & \\
\hline & 6.1.e Areas with natural or other restrictions & \\
\hline \multirow{2}{*}{$\begin{array}{l}6.2 \text { Incomes } \\
\text { of farmers }\end{array}$} & 6.2.a Direct support mechanisms & \\
\hline & 6.2.b Risk management in agriculture & Goal 2 (sub-goal 2.4) \\
\hline \multirow{3}{*}{$\begin{array}{l}\text { 6.3 Competitiveness } \\
\text { of agriculture }\end{array}$} & $\begin{array}{l}\text { 6.3a Modernization, innovation and digital } \\
\text { technologies in agricultural holdings }\end{array}$ & \multirow[t]{2}{*}{ Goal 2 (sub-goal 2.3) } \\
\hline & 6.3.b Market position of farmers & \\
\hline & 6.3.c Qualification and knowledge of farmers & Goal 2 (sub-goal 2.a) \\
\hline \multirow{4}{*}{$\begin{array}{l}\text { 6.4 Role of the } \\
\text { agricultural sector } \\
\text { for protection } \\
\text { of the environment }\end{array}$} & 6.4.a Agri-environmental commitments & \multirow{3}{*}{ Goal 2 (sub-goal 2.4) } \\
\hline & 6.4.b Organic production & \\
\hline & 6.4.c Irrigated agriculture & \\
\hline & 6.4.d Forest resources management & Goal 15 (sub-goal 15.2) \\
\hline \multirow{3}{*}{$\begin{array}{l}6.5 \text { Fisheries and } \\
\text { Aquaculture } \\
\text { Management }\end{array}$} & 6.5.a Fisheries and aquatic biological resources & \multirow{3}{*}{ Goal 14} \\
\hline & $\begin{array}{c}\text { 6.5.b Competitiveness of the fisheries and } \\
\text { aquaculture industries }\end{array}$ & \\
\hline & 6.5.c Blue economy and fishing communities & \\
\hline
\end{tabular}

Source: Developed by the author 
From the information contained in the third column of Table 1, it can be concluded that four of the five sub-priorities for development of sustainable Bulgarian agriculture correspond to several of the sub-objectives of Goal 2; the fourth sub-priority concerns part of Goal 15, and the fifth sub-priority corresponds to Goal 14 .

A more specific description of the goals is given in the official documents [3]. Here, attention is paid to the main guidelines in summary form.

Goal 2 Zero hunger is related to achieving food security, better nutrition and promoting sustainable agriculture. Sub-goal 2.3. is aimed at doubling agricultural productivity and the income of small-scale food producers (especially women), and 2.4. - ensuring sustainable food production systems and climate change. Sub-goal 2a includes increasing investment in rural infrastructure and agricultural research through international cooperation.

Goal 14 Life below water and, in particular conserve and sustainably use the oceans, seas and marine resources has a total of 10 sub-objectives, which are related to reducing marine water pollution, preventing adverse impacts on marine and coastal ecosystems, tackling the increasing acidity of the oceans, regulating fish production, banning certain forms of subsidies for the fisheries sector, promoting research in the field, providing access to markets for fishermen engaged in traditional fishing in small quantities and for food, etc.

Goal 15 Life on land, respectively sub-objective 15.2, is aimed at sustainable management of all types of forests, stopping deforestation, restoring damaged forests and increasing afforestation and reforestation worldwide.

Bulgaria, as a member state of the European Union (EU), needs to comply with the objectives of the Common Agricultural Policy (CAP). The vision of the European Commission (EC) on the CAP for the period 2021-2027 is aimed at developing a sustainable and competitive agricultural sector by achieving the objectives of the European Green Pact, in particular with regard to the Farm to Fork Strategy and the Biodiversity Strategy. In this regard, the EC sets nine specific objectives which are [4]: to ensure a fair income to farmers; to increase competitiveness of agriculture; to rebalance the power in the food chain; climate change action; environmental care; to preserve landscapes and biodiversity; to support generational renewal; vibrant rural areas and to protect food and health quality.

When comparing the sub-priorities of the National Programme BULGARIA 2030, in its part "Sustainable Agriculture", with the specific objectives of the CAP for the period 2021 2027, a high degree of compliance is expected to be confirmed. An exception is the uncovered at national level goal of preserving food quality and protecting health. In order to achieve sustainable Bulgarian agriculture, this direction of development must also be covered. This fact predetermines the need to include more areas of impact that correspond to the other two UN SDGs - Goal 3 Good health and Goal 12 Responsible consumption.

Under Goal 3, the sub-objective, which is directly related to agriculture, is $3.9-\mathrm{a}$ significant reduction in deaths and diseases resulting from pollution and contamination of air, water and soil. Goal 12 is with 11 targets, Goal 12 is with 11 targets, which cover sustainable management and efficient use of natural resources, reduction of resource waste, waste reduction, implementation of sustainable practices, technological capacity to more sustainable patterns of consumption and production, etc.

Another difference between the national and European priorities is that the development of sustainable agriculture in Bulgaria requires balancing between the main sectors. In the scientific literature [5], it is pointed out that specialized agricultural production structures have better economic results than mixed ones. Therefore, the level of specialisation of farms must be taken into account when seeking balance.

Based on the above, it can be summarized that, when reporting the results of the actions taken to achieve sustainable agriculture, the following five goals should be covered: Goal 2: Zero hunger, Goal 3: Good health, Goal 12: Responsible consumption, Goal 14: Life below water and Goal 15: Life on land. 


\section{Methods and data}

From a theoretical point of view in studying the progress towards sustainable development, including sustainable development of agriculture, different approaches are applied. In the further exposure, some contemporary studies on this issue, in order to justify the methodology are presented.

In a recent study [6], a model for sustainable development, including six indicators, is presented. The authors set possible limits for achieving sustainable development. The distances between the values of the indicators and their corresponding limits represent the opportunities for sustainable development. Then, through cluster analysis, 117 countries are grouped into six clusters based on similar challenges facing sustainable development for the period 2010-2015. The results of the analysis show that some countries are more advanced in their actions in coordination with SDGs and consequently reduce the space until they are fully achieved. When selecting clusters, the square of Euclidean distance and the k-means algorithm are used.

In addition to the global level, progress towards sustainable development can be seen at other levels. Such a study [7] is conducted for the 35 OECD countries. The authors study the state and dynamics of variables that are part of the SDGs. A coefficient of variation is used to measure the convergence of socio-economic indicators, and the presence of a linear relationship between pairs of variables is checked by correlation and regression analysis. A multivariate approach is applied in the study, including cluster analysis and principal components analysis. The observed indicators are 15, including: GDP per capita and the real change in GDP per capita relative to variables for economic activity, etc. In clustering, 5 clusters are separated. Highly developed countries are divided into two clusters - one with 15 countries and the other - with 8 . The fourth cluster includes the lagging countries. The article also concludes that such an analysis can be useful for governments in finding weaknesses and ways to overcome them to achieve the goals of the 2030 Agenda.

In the field of agriculture, a team of authors [8] characterize the discrepancy in the development of agriculture and the food industry in the EU-28. For this purpose, they study the dynamics of selected global indicators for the development of agriculture and food industry in the period 2002 - 2013 (divided into three sub-periods). To analyze the discrepancy, the authors use cluster analysis to group the countries into homogeneous clusters, i.e. groups of countries with similar indicators. The selected indicators are: agricultural raw materials import, agricultural raw materials exports, crop production index, livestock production index, food production index, cereal yield, agricultural sector's value added and agricultural sector's value added per worker. The results of the empirical study, using the Ward method for cluster analysis, show the separation of three homogeneous groups. Bulgaria falls into the second cluster, along with: Austria, Croatia, Estonia, Germany, Greece, Portugal and Great Britain, although during the separate sub-periods, the composition of the countries changes. The general conclusion is that despite the different starting positions of the countries, after their accession to the EU, they have the same direction of development, but for the period under review significant differences in the value added per worker in agriculture are revealed.

The problems and prospects for the sustainable development of agribusiness at the national level (Bulgaria) have been studied by authors [9], who set out approaches to sustainable nature management within ecological capacity, in coordination among the political, economic and social systems; offer models for sustainable nature management based on organic farming; highlight the benefits of sustainable agriculture as a form of reducing unemployment in certain regions, reducing migration processes and strengthening the local economy. In another study [10], the focus is again on the EU-28, but the subject is the UN SDGs and, in particular, the social dimension. Twelve indicators for the period 2012 
- 2016 are selected and Hierarchical Cluster Analysis (HCA) and Principal Component Analysis (PCA) are applied. Statistical data are obtained from various sources. The results of the analysis show the formation of four clusters: cluster 1 - the most developed countries in the EU, i.e. those with the best performance; cluster 2 - the least developed countries, i.e. the lowest performing countries; cluster 3 covers economies in transition, i.e. second in terms of performance and cluster 4 - including the southern countries, rated as the second, lowest performing cluster. Bulgaria, along with Greece and Romania, have been identified as the countries with the least progress in achieving the SDGs.

Differences between EU countries in terms of achieving the UN SDGs have been studied by another team of authors [11]. They cover all three dimensions of sustainable development (economic, social and environmental). The statistical methods used are: Principal Component Analysis and Hierarchical Cluster Analysis. The authors conclude that the differences between EU countries in terms of their sustainable development are mainly due to economic and social indicators, such as: income / poverty; health; education / employment. On this basis, two groups of countries in the EU are distinguished: the first - the countries of Western and Northern Europe ("rich") and the second - the countries of Eastern and Southern Europe ("poor"). The statistical data for conducting the survey are derived from Eurostat - 83 indicators. The second group, whose indicators are defined as average, is divided into three subgroups. Bulgaria falls into the second subgroup with the Baltic States (Estonia, Lithuania and Latvia) and Romania.

From the reviewed scientific publications, it can be summarized that the measurement of progress towards achieving the SDGs is carried out both globally and at other levels - OECD and EU countries. The main goal of the research is to separate homogeneous groups (clusters) which is successfully done by applying hierarchical cluster analysis. As a result, it is possible to compare the differences between the clusters and, respectively, between the countries in the individual clusters and to look for solutions to overcome the differences. Furthermore, the analysis uses statistical data from different sources and for individual periods, which makes it difficult to track trends over time. However, Bulgaria is defined as a country with insufficient progress towards achieving the SDGs. In addition, industry analyses are less common. There is also a great variety of indicators included in the analysis and used for clustering.

Based on the conclusions synthesized from a theoretical and methodological point of view, the present study applies hierarchical cluster analysis to classify EU countries (excluding the UK) according to their progress towards achieving SDGs related to agriculture. There are numerous publications $[12,13]$ on the stages of the cluster analysis procedure. Here we adhere to the following sequence [14]: 1) choice of variables; 2) filtering and data preparation; 3) correlation analysis; 4) classification by hierarchical cluster analysis; 5) assessment of cluster validity by ANOVA; 6) post hog multiple comparison test - Tukey HSD - as an aid to interpreting the results. The calculations are performed with SPSS.

Information on individual countries' progress towards sustainable development under the 17 SDGs is contained in a specialized report [15]. In it, based on the SDG Index, each country receives a rank. From a methodological point of view, for each of the goals there are separate indicators, the trend of which is reported. Four main categories with indicative colors are defined: green color - the goal is achieved (on track or maintaining achievement); yellow color - challenges remain (moderately increasing); orange - significant challenges remain (stagnating) and red - major challenges remain (decreasing). The cases when the information is not available are marked in grey. The rank is from 0 to 100 , where 100 being the best level and 0 being the worst. In the 2020 report, the SDG Index for Bulgaria ranked it 39th out of 166 countries covered in the survey, i.e. our country is below average.

In this study, the subject is narrowed to EU level. On the one hand, the focus of the study is on agriculture, respectively on five of the 17 objectives. These are the variables on the 
basis of which the clustering is performed (Goal 2: Zero hunger, Goal 3: Good health, Goal 12: Responsible consumption, Goal 14: Life below water and Goal 15: Life on land). On the other hand, only the 27 EU countries (excluding the United Kingdom) are observed. In this way, a similarity can be established in the development of sustainable agriculture in Europe. Data from the five selected goals for the EU countries are filtered from this database, thus fulfilling the first and second steps of the analysis sequence.

\section{Grouping of EU countries according to the degree of achievement of the goals for sustainable agriculture}

Before proceeding with the cluster analysis, it is necessary to determine the strength of the relationships between the selected variables (step 3). The results of the correlation analysis, in which the Pearson coefficient is used, are presented in Table 2.

Table 2. Correlations

\begin{tabular}{|c|c|c|c|c|c|c|}
\hline \multicolumn{2}{|c|}{} & Goal 2 & Goal 3 & Goal 12 & Goal 14 & Goal 15 \\
\hline Goal 2 & Pearson Correlation & 1 & 0,241 & $-0,047$ & 0,087 & $-0,186$ \\
\cline { 2 - 8 } & Sig. (2-tailed) & & 0,227 & 0,816 & 0,667 & 0,352 \\
\hline \multirow{2}{*}{ Goal 3 } & Pearson Correlation & 0,241 & 1 & $-0,241$ & $-0,094$ & $-0,497^{* *}$ \\
\cline { 2 - 7 } & Sig. (2-tailed) & 0,227 & & 0,227 & 0,642 & 0,008 \\
\hline \multirow{2}{*}{ Goal 12 } & Pearson Correlation & $-0,047$ & $-0,241$ & 1 & $-0,177$ & 0,079 \\
\cline { 2 - 7 } & Sig. (2-tailed) & 0,816 & 0,227 & & 0,378 & 0,694 \\
\hline Goal 14 & Pearson Correlation & 0,087 & $-0,094$ & $-0,177$ & 1 & 0,097 \\
\cline { 2 - 7 } & Sig. (2-tailed) & 0,667 & 0,642 & 0,378 & & 0,632 \\
\hline \multirow{2}{*}{ Goal 15 } & Pearson Correlation & $-0,186$ & $-0,497^{* *}$ & 0,079 & 0,097 & 1 \\
\cline { 2 - 7 } & Sig. (2-tailed) & 0,352 & 0,008 & 0,694 & 0,632 & \\
\hline & $* *$ Correlation is significant at the 0.01 level (2-tailed). \\
\hline
\end{tabular}

The calculated coefficients show the presence of different power relationships between the variables, but they are not statistically significant. This means that it is not necessary to remove any of the selected SDGs from the analysis. The only statistically significant relationship is observed only between goal 3 and goal 15 and it is negative.

Table 3. Cluster Membership

\begin{tabular}{|c|c|c|c|c|c|}
\hline Country & 4 Clusters & Country & 4 Clusters & Country & 4 Clusters \\
\hline 1:AUT & 1 & $10: F R A$ & 2 & $19:$ MLT & 1 \\
\hline 2:BEL & 1 & $11: \mathrm{DEU}$ & 1 & $20: \mathrm{NLD}$ & 1 \\
\hline 3:BGR & 2 & $12: \mathrm{GRC}$ & 2 & $21: \mathrm{POL}$ & 3 \\
\hline 4:HRV & 2 & $13: \mathrm{HUN}$ & 3 & $22: \mathrm{PRT}$ & 1 \\
\hline 5:CYP & 2 & $14: \mathrm{IRL}$ & 2 & $23: \mathrm{ROU}$ & 3 \\
\hline 6:CZE & 3 & $15: \mathrm{ITA}$ & 1 & $24: \mathrm{SVK}$ & 3 \\
\hline 7:DNK & 1 & $16: \mathrm{LVA}$ & 4 & $25: \mathrm{SVN}$ & 1 \\
\hline 8:EST & 4 & $17: \mathrm{LTU}$ & 4 & $26: \mathrm{ESP}$ & 1 \\
\hline 9:FIN & 2 & $18: \mathrm{LUX}$ & 1 & $27: \mathrm{SWE}$ & 2 \\
\hline
\end{tabular}

The next step 4 is to perform the cluster analysis. Hierarchical cluster analysis by the Ward method is applied and the squared Euclidean distance is used as a measure of the 
distance between the clusters. Four clusters have been formed. In the Table 3 , the participation of each of the countries in the respective cluster is indicated.

Cluster 1 includes 11 countries: Austria, Belgium, Denmark, Germany, Italy, Luxembourg, Malta, the Netherlands, Portugal, Slovenia and Spain. Cluster 2 includes 8 countries: Bulgaria, Croatia, Cyprus, Finland, France, Greece, Ireland and Sweden. Cluster 3 unites 5 countries: The Czech Republic, Hungary, Poland, Romania and Slovakia, and cluster 4 groups together 3 countries: Estonia, Latvia and Lithuania.

The grouping can be traced from the dendrogram (see Fig. 1). The states are fixed along the vertical axis and the distances between the clusters are fixed along the horizontal axis. In the upper part of the tree structure is cluster 1, below it is cluster 3, followed by cluster 4 and in the lower part - cluster 2 . The close location of the vertical lines, of the individual countries to the vertical axis, testifies to the similarity in the variables. If it is traced how the countries are grouped at a greater distance from the vertical axis, it can be found that the $27 \mathrm{EU}$ countries (excluding the United Kingdom) are divided into two large groups. Cluster 1 and cluster 3 are in the first group and cluster 4 and cluster 2 are in the second group.

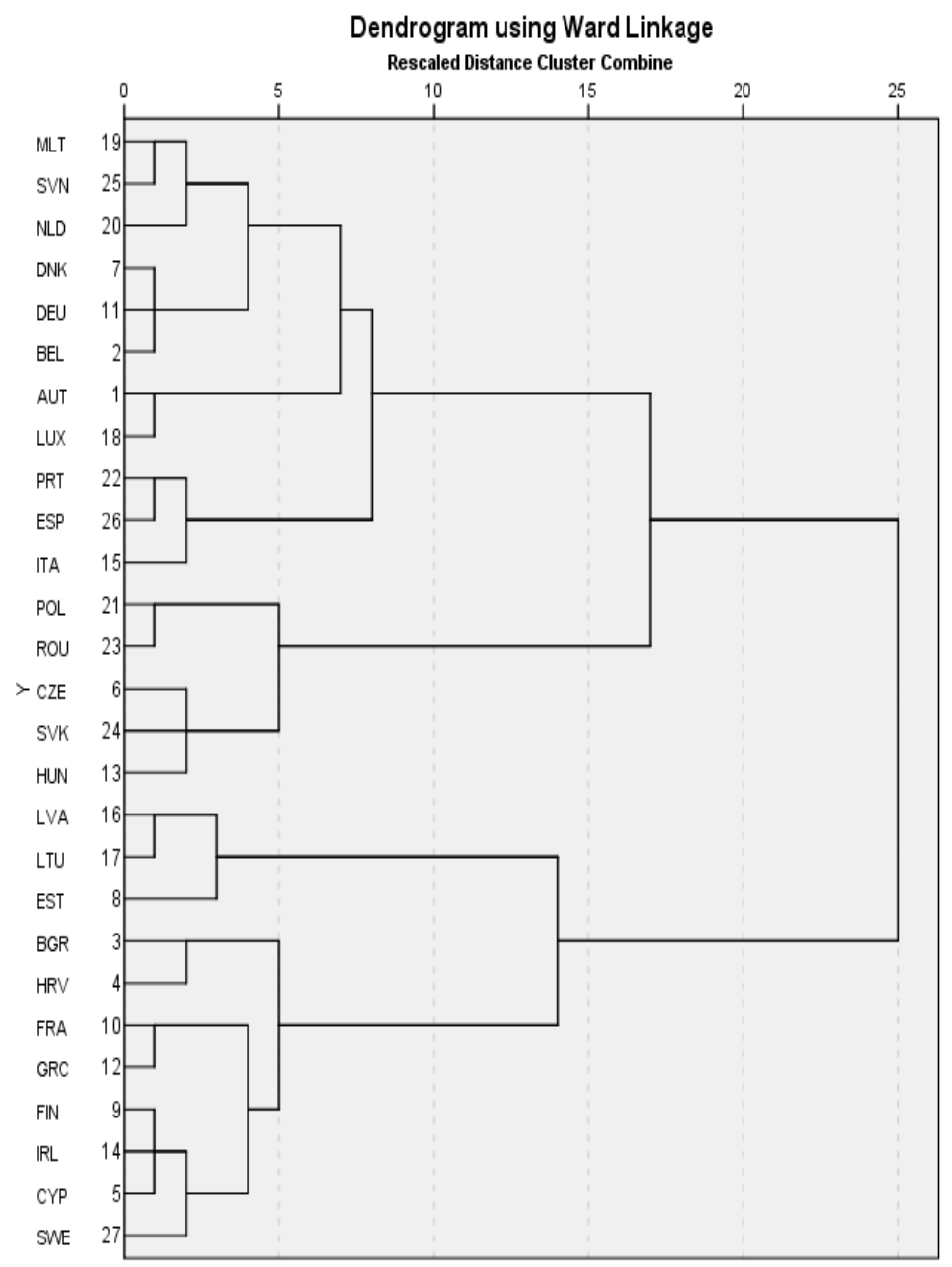

Fig. 1. Dendogram

In order to determine whether the separate four clusters are valid (step 5), it is necessary to perform a one-way analysis of variance (ANOVA). This is one of the possible techniques 
used in such cases. It reveals the existence of equality between the averages in the individual clusters for each of the variables of the clustering. Fisher's F-test is used as a measure. The results of the one-way analysis of variance are presented in Table 4. The calculated values in the last column of Table 4 show that the F-criterion is statistically significant in all four clusters or, with $95 \%$ certainty, it can be stated that there are clusters with different averages for each variable, i.e. the differences between the clusters are valid.

Table 4. ANOVA

\begin{tabular}{|c|c|c|c|c|c|c|}
\hline \multicolumn{2}{|c|}{} & Sum of Squares & df & Mean Square & F & Sig. \\
\hline \multirow{4}{*}{ Goal 2 } & Between Groups & 2,369 & 3 & 0,790 & 4,625 & 0,011 \\
\cline { 2 - 7 } & Within Groups & 3,927 & 23 & 0,171 & & \\
\cline { 2 - 8 } & Total & 6,296 & 26 & & & \\
\hline \multirow{4}{*}{ Goal 3 } & Between Groups & 3,683 & 3 & 1,228 & 5,665 & 0,005 \\
\cline { 2 - 8 } & Within Groups & 4,984 & 23 & 0,217 & & \\
\cline { 2 - 8 } Goal 12 & Total & 8,667 & 26 & & & \\
\hline \multirow{4}{*}{ Goal 14 } & Between Groups & 2,614 & 3 & 0,871 & 5,444 & 0,006 \\
\cline { 2 - 8 } & Within Groups & 3,682 & 23 & 0,160 & & \\
\cline { 2 - 8 } & Total & 6,296 & 26 & & & \\
\hline & Wetween Groups & 12,646 & 3 & 4,215 & 13,881 & 0,000 \\
\hline & Within Groups & 6,984 & 23 & 0,304 & & \\
\hline \multirow{3}{*}{ Goal 15 } & Total & 19,630 & 26 & & & \\
\cline { 2 - 8 } & Within Groups & 8,425 & 3 & 2,808 & 11,901 & 0,000 \\
\cline { 2 - 8 } & Total & 13,427 & 23 & 0,236 & & \\
\hline
\end{tabular}

In the next stage (step 6), it is established what is the reason for the difference / similarity between the valid clusters. For this purpose, the analysis continues with a post hog multiple comparisons test - Tukey HSD (see Appendix 1).

Based on the conducted test for multiple comparisons, it can be summarised that there are certain significant differences between the clusters. In Goal 2, there are statistically significant differences between cluster 2 and cluster 4 . In Goal 3, the differences are significant in cluster 1 versus cluster 4 and in cluster 2 versus cluster 4 . In Goal 12, cluster 3 differs from the other three clusters. In Goal 14, the differences are significant for cluster 1 versus cluster 2 and cluster 4 , for cluster 2 versus cluster 1 and cluster 3, for cluster 3 versus cluster 2 and cluster 4 , and for cluster 4 versus cluster 1 and cluster 3. In Goal 15, cluster 1 differs from cluster 3 and cluster 4, cluster 2 - from cluster 3 and cluster 4 , cluster 3 - from cluster 1 and cluster 2 and cluster 4 - from cluster 1 and cluster 2.

The interpretation of the similarities among the countries in the different clusters in achieving the goals related to sustainable agriculture in Europe is as follows:

$>$ Cluster 1 countries are characterized by a moderate increase in Goal 3 indicators, i.e. they still face challenges and major challenges under Goal 12 and Goal 14. Regarding Goal 2 and Goal 15, the countries in cluster 1 are divided in two sub-groups. The first sub-group includes Austria, Belgium, Italy and Luxembourg, which face significant Goal 2 challenges, and for Goal 15 - for three of the countries (Belgium, Denmark and Germany) the challenges are smaller, while for the other three (Austria, Italy and Luxembourg) the challenges are larger. The second subgroup (Malta, the Netherlands, Portugal, Slovenia and Spain) is at the lowest level to achieve Goal 2 and for Goal 15 there is a stagnation in the indicators.

$>$ The countries in cluster 2, which includes Bulgaria, together with Croatia, Cyprus, Finland, France, Greece, Ireland and Sweden are characterized by significant challenges to 
achieve Goal 2 and Goal 14, remaining challenges for Goal 3and Goal 14 and major challenges for achieving Goal 12.

$>$ The countries in cluster 3 (Czech Republic, Hungary, Poland, Romania and Slovakia) are characterised by significant challenges in relation to Goal 2, Goal 3 and Goal 12, and in Hungary and Slovakia the challenges under Goal 2 are even greater. With regard to Goal 14, it can be said with certainty that Poland and Romania face major challenges, while in the other three countries there is no available information which can be considered a serious challenge, as no recommendations for action can be given. The improvement of the Goal 15 indicators is positive for the countries in this cluster - in Hungary, Poland and Romania the goal has been achieved.

$>$ The countries in cluster 4 (Baltic States: Estonia, Latvia and Lithuania) have the same characteristics on four of the goals - achieved Goal 15, significant challenges under Goal 3 and major challenges under Goal 2 and Goal 12. The differences are only under Goal 14, where Estonia is best represented with a moderate increase in indicators, followed by Lithuania with a stagnation in indicators and Latvia - with a decrease in indicators.

\section{Conclusion}

The classification of European countries according to the degree of achievement of SDGs related to agriculture groups the countries into four statistically significant clusters. Five years after the start of the 2030 Agenda, it can be generally concluded that EU countries are far from developing sustainable agriculture. By individual goals, the results show the following:

- the greatest progress is reported in reaching Goal 15, as the countries of cluster 4 and cluster 3 have achieved it; and for six of the eight countries in cluster 2, and for five of the eleven in cluster 1 , small challenges remain;

- in second place, by positive trends in the indicators, Goal 3 is ranked. The countries of cluster 1 and cluster 2 are approaching its achievement, but challenges remain. Luxembourg (cluster 1) and Sweden (cluster 2) have achieved this. For countries in cluster 3 and cluster 4 , the challenges are greater;

- in the third place, the implementation of Goal 2 and Goal 14 can be positioned. The countries of cluster 2 face significant challenges for both goals, and the countries of the other three clusters face, in most cases, major challenges;

- in the last place, the implementation of Goal 12 is positioned. The countries in cluster 3 have made some progress on it. The same can be said for Italy, Portugal and Spain (cluster 1) and Bulgaria and Croatia (cluster 2). The other countries in cluster 1 and cluster 2, as well as all in cluster 4, are at the lowest level in achieving Goal 12.

Therefore, over the next 10 years, active work must be done to achieve sustainable agricultural development in the EU. The remaining small challenges of ensuring a healthy life for all (Goal 3) cannot be overcome without achieving food security (Goal 2) and responsible consumption and production (Goal 12), where the challenges are greater.

Carrying out an annual classification of EU countries, according to this methodology, makes it possible to monitor both individual progress and comparability at the interstate level. The results would be useful to the specialized ministries in proposing measures and actions in the short and medium term.

\section{References}

1. UN. Transforming our world: the 2030 Agenda for Sustainable Development, Resolution adopted by the General Assembly (2015) 
2. Council of Ministers, BULGARIA 2030, The National Development Programme. Detailed Strategies, Minutes № 67 of the Council of Ministers of 02.12.2020, https://www.minfin.bg/bg/1394

3. Transforming our world: The 2030 Agenda for Sustainable Development. Collection of documents, The United Nations Association of Bulgaria, Sofia, 28-43 (2016)

4. European Commission. Future of the common agricultural policy, https://ec.europa.eu/info/food-farming-fisheries/key-policies/common-agriculturalpolicy/future-cap_bg

5. S. Petrova, Influence of the Specialisation of the Agricultural Production on the Assortment Supply, in Proceedings of the International Scientific and Practical Conference "State and Problems in the Management and Development of Agriculture", Svishtov, D. A. Tsenov Academy of Economics, 278-279 (2019)

6. K. Linnerud, E. Holden, M. Simonsen, Sust. Dev., 1-16 (2021), doi: 10.1002/sd.2171

7. S. Megyesiova, \& V. Lieskovska, Sustainability, 10, (2018); doi:10.3390/su10124554

8. M. Reiff, Z. Ivanicova, K. Surmanova, Agric. Econ. - Czech, 64, 197-205 (2018)

9. M. Nikolova, M. Linkova, X. Ferhad, “Scientific Research” Almanac, 21, 414-472 (2014)

10. M. Drastichová, P. Filzmoser, Probl. Ekor., Vol. 14, nr 2, 7-24 (2019)

11. J-P. Cling et al. The Differences between EU Countries for Sustainable Development Indicators: It is (mainly) the Economy! Insee, (2019)

12. E. Mooi, M. Sarstedt, A Concise Guide to Market Research The Process, Data, and Methods Using IBM SPSS Statistics, Berlin Heidelberg, (Springer-Verlag, 2011)

13. M. R. Anderberg, Cluster analysis for applications, New York, San Francisco, (Academic Press, INC, 1973)

14. V. Perkov, The European countries classification based on the level of their Businessto-business e-commerce development, in Yearbook of D. A. Tsenov Academy of Economics - Svishtov, CXIX, 247-253 (2016)

15. J. Sachs et al. The Sustainable Development Goals and COVID-19. Sustainable Development Report 2020, (Cambridge: Cambridge University Press, 2020) 